\title{
Identities and Beliefs in ESL Writing: From Product to Processes
}

\section{Xuemei Li}

Studies investigating cultural influences on second-language writing have been mainly product-oriented. Moreover, research on writing processes has mostly focused on the strategies of writing and learning to write. Writing processes where we can see the evolution of the writer's identity and beliefs have been less adequately addressed. Therefore, this article focuses on the dynamic relationship of culture, identity, and beliefs with regard to the writing process (the micro-process) and the process of learning to write (the macro-process) in the ESL context. A study consisting of two cases was undertaken to examine the reconstruction of the writer's identity and the evolution of the learner's beliefs in an ESL context. Data for Case A include writings by and interviews with a first-year ESL student; data for Case B include class observations of and interviews with students and their teacher in an ESL writing class. It has been found that the notions of culture, identity, and beliefs are interwoven; they work together to reshape learners' beliefs in terms of education and writing and to reconstruct a writer's identity that incorporates multiple influences and multiple intentions. Recommendations are offered for guiding ESL students in the exploration of their first and host cultures and for facilitating the evolution of beliefs and the reconstruction of identities.

Les études portant sur les éléments culturels qui influencent l'écriture en langue seconde sont surtout axées sur le produit. De plus, la recherche sur les processus de rédaction portent principalement sur les stratégies et l'apprentissage de l'écriture. Les processus de rédaction qui permettent de voir l'évolution de l'identité et des croyances de l'auteur ont moins souvent fait l'objet d'études. Cet article porte donc sur le lien dynamique entre la culture, l'identité et les croyances par rapport à l'écriture (le microprocessus) et l'apprentissage de l'écriture (le macroprocessus) dans un contexte d'ALS. Nous avons entrepris une étude de deux cas dans un milieu d'ALS pour examiner la reconstruction de l'identité de l'auteur et l'évolution de ses croyances. Les données pour le cas 'A' provenaient des rédactions écrites par un élève de première année en ALS et des entrevues avec lui; celles pour le cas ' $B$ ' étaient tirées de sessions d'observation d'une classe de rédaction en ALS et d'entrevues avec l'enseignant et les élèves. Les résultats indiquent que la culture, l'identité et les croyances sont des notions qui s'entrelacent, qui, ensemble, remodèlent les croyances des apprenants par rapport à l'éducation et à la rédaction, et reconstruisent leur identité basée sur une multi- 
plicité d'influences et d'intentions. Nous offrons des recommandations qui visent à appuyer les élèves en ALS dans leur exploration de leur culture d'origine et leur culture d'adoption, et à faciliter l'évolution de leurs croyances et la reconstruction de leur identité.

\section{Background of the Study}

Research on ESL writing has gone through an evolution; four strands of studies are significant in examining the multiple facets of this field. The first strand consists of studies focusing on comparative rhetoric; the second relates to studies of the writing processes and strategies of ESL writers; the third includes studies of beliefs about language learning, education, and writing; and the fourth represents studies involving the notion of identities in ESL writing. Only recently have these four strands of research begun to be integrated.

Cultural differences have historically provided an explanation for the gap that second-language learners have to bridge. One of the main foci for investigation in the field of writing research has been contrasting features between Eastern and Western cultures. Inquiry into how culture influences Asian students' writing in a Western academic setting started with the understanding of generally how these two cultures differ in terms of such aspects as thought patterns, discourse traditions, and educational ideologies. The influence of Kaplan's $(1966,1987)$ notion of cultural thought patterns has lasted until recent years. The existence of culture-specific rhetorical styles was supported by a number of studies from varying perspectives such as those of Conner and Lauer (1988), Ballard and Clanchy (1991), and Hinkel $(1994,1995)$. It was found that in East Asian traditions there exists a tendency to value appreciation over criticism, summary over analysis, and reproduction over originality: as a result, it could be supposed that Eastern students' circuitous introductions or efforts to achieve harmony might not meet the requirement of critical judgment as envisaged by Western teachers.

This concept of cultural thought patterns was supported in the field of psychology by Nisbett, Peng, Choi, and Norenzayan (2001), who found that people raised in diverse cultures think in various ways. According to them, East Asians tend to think more holistically. They are more sensitive to context and more tolerant of contradiction; they make relatively little use of categories and formal logic. These cultural traits are believed to show the strong influence of Taoist thought, in which complexity and dialectical argument are appreciated. On the other hand, Westerners are said to be more analytic in their thinking. They are eager to resolve contradiction and more dependent on the rules of formal logic. This Occidental thinking seems to be in line with the ancient Greek tradition of adversarial debate, in which formal 
logical argument and analytic deduction are common tools for argumentation.

Throughout this body of research on cultural differences, there was an attempt to connect culture with specific features of written texts. However, the traditional methodology of analyzing written texts for cultural tendencies in writing seemed insufficient to explain how an ESL learner might construct a new identity in writing. What seemed more crucial was to examine the processes by which ESL students learn to write and to present themselves in writing, and how ESL writers' identities evolve during these processes.

Another strand of research on second-language writing moved away from written texts and began to focus on the writing process (Donaldson, 1990; Woods, 1984; Zamel, 1983). I propose categorizing the writing process into the micro-process (the actual composing process) and the macro-process (the process of learning to compose): writing-process research has mostly focused on the micro-process, examining strategies used by second-language writers - such as freewriting, drafting, and peer feedback — with the assumption that students would become effective writers if they were taught effective strategies. However, it has been found that students do not welcome all writing strategies unanimously (Leki \& Carson, 1994; Mangelsdorf \& Schlumberger, 1992). Some may reject one strategy as useless, but be ready to accept another (Woods, 1984). Researchers therefore directed their attention to the fact that culturally diverse students may have differing attitudes toward these practices as a result of their prior learning backgrounds (Ashwell, 2000; Carson \& Nelson, 1996; Hedgcock \& Lefkowitz, 1994; Zhang, 1995).

A large number of studies investigate such micro-process practices as freewriting (Lee, 1999), peer review (Mangelsdorf \& Schlumberger, 1992; Mendonça \& Johnson, 1994; Stanley, 1992; Zhu, 2001), and teacher feedback (Diab, 2005; Ferris 1999, 2004; Ferris \& Roberts, 2001; Hyland \& Hyland, 2001; Jacobs, Curtis, Braine, \& Huang, 1998; Leki, 1991; Truscott, 1996, 1999). By contrast, fewer studies target the macro-process through which ESL students learn to write (Leki \& Carson, 1994). In fact students' attitudes toward macroprocess writing strategies and their understanding of the relationship between the micro- and the macro-processes can reflect their culture-based perceptions about writing and language learning. For example, in Carson and Nelson's (1996) study, Chinese and Spanish ESL learners' varying perceptions of the goal of group discussion and how they offered feedback were seen to be affected by their respective cultural beliefs.

This brings us to research on beliefs in the ESL context: a third strand of research in the language-learning literature focuses on the beliefs of language learners. Researchers such as Horwitz (1999) have examined how language learners' beliefs influence the approaches they take to language learning and 
the strategies they use. Recent research has looked at beliefs about education and attitudes toward it from a cultural perspective. Tweed and Lehman (2002) are among those investigating the differences between Confucian and Socratic ideologies with respect to education. They maintain that "Socrates tended to question his own and others' beliefs, evaluated others' knowledge, esteemed self-generated knowledge, began teaching by implanting doubt, and sought knowledge for which he had good reasons" (p. 90); whereas, "Confucius was humanistic and sought to achieve societal harmony by encouraging virtuous activity" (p. 89). Ballard and Clanchy (1991) characterize East Asian education as "reproductive," which for them means based on memory and imitation, and Western education as "analytical," which means encouraging critical thinking and questioning; as a result, they note that Eastern teachers strive to impart "correct" answers to students, whereas their Western counterparts endeavor to initiate "originality" in students (pp. 2122). Thus it is noted that Confucian ideologies pertaining to education have had a profound and persistent influence in China and in East Asian countries that have had close ties with traditional Chinese culture: traditional attitudes toward knowledge shape preferred educational processes (Ballard \& Clanchy) and further shape people's beliefs about appropriate approaches to learning and teaching and appropriate roles for learners and teachers.

Beliefs about the process of composing can be culturally diverse (Carson \& Nelson, 1996). Some strategies used in the writing process, seemingly distinct from the notions of culture and identity, in fact have implicit connections with them. For example, ESL students' beliefs about peer response and teacher feedback, which may be complicated and different from what teachers expect, can be related to first-cultural conventions. Studies by Nelson and Carson (1998) and by Zhang (1995) indicate ESL students' frustration that many of the problems pointed out by their peers were not very effective in helping them say what they wanted to say. It was also found that Chinese students considered maintaining group harmony more important than offering feedback (Carson \& Nelson) and therefore were reluctant to identify problems, judging that "making negative comments on a peer's draft leads to division, not cohesion, in a group" (p. 128).

Despite the argument over the effectiveness of feedback from teachers (Ferris, 1999, 2004: Leki, 1991; Truscott, 1996, 1999), most research findings point out that explicit teacher feedback can play a positive role (Ferris \& Roberts, 2001; Hyland, 1998). In the second-language context, teachers' specific, idea-based, and meaning-level comments can lead to substantial student revisions that improve the quality of writing. Teacher feedback on multiple drafts is particularly effective in promoting student revision (Paulus, 1999). However, beliefs differ with regard to the types of feedback that are believed to work best. Hyland and Hyland (2001) point out that despite teachers' good intentions, their mitigation of criticism can often lead 
to ambiguity in meaning, and Nelson and Carson (1998) suggest that some students may prefer negative comments if they show exactly where their problems are. In fact students' beliefs about teacher feedback partly encode their cultural perceptions of the roles of teacher and learner. The Confucian precept is that teachers are authorities; therefore, teachers' feedback should be respected. Meanwhile, teachers should be strict; negative feedback is considered the bitter medicine that cures the disease, as a popular saying goes.

Students from East Asian countries tend to perceive good teachers first of all, as having profound knowledge in their subject area, in keeping with the Confucian notion of the purpose of teaching as the transmission of knowledge (Cortazzi \& Jin, 1996). At the same time, good students should work hard to memorize the knowledge that the teacher imparts and to show respect for and obedience to the teacher (Lee, 2000). In class, students are expected to give thoughtful opinions rather than of spontaneous responses (Cortazzi \& Jin). This characteristic can become a handicap when students are asked to do peer conferencing and peer evaluation. Whereas teachers' intentions are to train students to become critical writers through these activities, students may attach more importance to the issue of authority, as well as to the issues of saving face and maintaining group harmony.

It must be admitted that "students' perceptions of themselves, their teachers, and classroom events and their role in those events, act as a filter between what is taught and what is learned" (Johnson, 1995, p. 52). Learning can be enhanced if students are able to perceive teachers' intentions accurately when setting certain tasks and expectations. However, coming from other cultural and educational backgrounds, ESL students are faced with a dual task: they have to study not only the language, but also the "code of conduct" (p. 52) expressed implicitly by the teacher and other people in the target language environment. It is often hard for them to see through the lens of the teacher; Nunan (1989), therefore, asserts that "there is evidence that we as teachers are focusing on one thing, [while] learners are focusing on something else" (p. 20).

Although beliefs are relatively resistant to change, they do alter when students have to adapt themselves to a new learning context (Woods, 2003). As arguably the most important individual in the ESL classroom, where "the teacher is the only native or near-native speaker of the language" (Johnson, 1995, p. 16), the instructor can have a profound influence on the learning that takes place there and on students' beliefs about what learning should be, as well as about the outcomes of that learning. However, the evolution of learner beliefs is complex. Because learners already possess some knowledge structures before they enter a university classroom, they may, especially in an ESL setting, have some different or even "idiosyncratic" understandings as compared with "those presupposed by the teacher" (Woods, 2003, p. 224). 
Such research on beliefs is insightful in that it not only probes ideologies about writing and education, but also has started to take a dynamic view of the influence of diverse cultures to which learners are exposed and to emphasize the evolving process of beliefs (Woods, 2003). However, one important connection has been underinvestigated: the interplay of learner beliefs and identity construction in ESL contexts.

The fourth strand of research considers the notion of identity, including both cultural identity and writer identity in second-language writing. Research along these lines was initially sparked by Shen's (1989) discussion of his struggles to establish in written text a second-cultural self that was distinct from his first-cultural self. According to Shen, the process by which a non-native speaker learns to write academic text in English at a Western university involves creating a new identity that meets the expectations of the professors or teachers representing the discipline of which the student is becoming a new member. Writer identity in the text inevitably references the author's cultural heritage, as well as his or her understanding of the ideologies in the host culture.

More recently, studies have begun a multidimensional examination of the construction of writer identity in second-language writing, looking at multiple elements that shape the writer's identity and at how these are manifested in texts (Hirvela \& Belcher, 2001; Ivanic, 1994, 1997; Kramsch, 1998; Thornborrow, 1999). This trend has gone beyond the traditional binary approach to analysis. For example, Kramsch articulates the multi-identity of individuals in connection with language: "Despite the entrenched belief in the one language $=$ one culture equation, individuals assume several collective identities that are likely not only to change over time in dialogue with others, but are liable to be in conflict with one another" (p. 67). Ivanic and Thornborrow also discuss the point that multiple facets-such as subject positioning and the social positioning of the speaker-determine a writer's identity.

A writer's voice in writing reveals the discourse community to which he or she belongs. However, even as a careful, thoughtful, and relatively permanent record of a person's mind, writing may not always portray the author's thoughts accurately. It may distort, exaggerate, or disguise the author's real intent in producing the text. Therefore, the notion of writer identity may have purposefully performative elements embedded in it (Clark \& Ivanic, 1997; Hirvela \& Belcher, 2001; Ivanic, 1997). All these ideas also apply to the issue of the writer's voice in academic writing. Because academic writing encompases "a variety of subject-specific literacies" (Hyland, 2002, p. 352) through which members of each discipline communicate with each other, the writer must adopt an appropriate identity by choosing a style and words that will appropriately interest and inform the reader in the specific discipline. 
One gap in the field stems from the fact that despite a limited number of studies on the influence of cultural identity on the construction of writer identity, little has been done to question how students' cultural identities and writer identities interplay with their beliefs about language learning and teaching, and how this interconnection between identity and belief systems affects the micro- and macro-processes in ESL writing. tions:

The present study, therefore, aims at addressing the following three ques-

1. What is the interplay of culture, writer identity, and learner beliefs in the product, micro-process and macro-process of ESL writing?

2. How do writer identity and learner beliefs influence the way ESL writers compose and learn to compose academic texts?

3. How do learner beliefs evolve, and how can this evolution be facilitated? To begin, it is valuable briefly to define the concepts of culture, writer identity, and learner beliefs. For the notion of culture, I adopt Kramsch's (1998) definition:

membership in a discourse community that shares a common social space and history, and common imaginings. Even when they have left that community, its members may retain, wherever they are, a common system of standards for perceiving, believing, evaluating and acting.

These standards are what is generally called their "culture." (p. 10)

The concept of writer identity reflects the multiple identities (e.g., ethnic identity, cultural identity, personal identity, etc.) of a person as expressed in written texts, but with some artificial and purposeful elements embedded in it. I borrow Clark and Ivanic's (1997; Ivanic, 1997) formulation that writer identity is composed of multiple aspects incorporating the writer's life history and sense of roots, self-representation and sense of authority in the text, and limitations on possibilities for selfhood.

To elaborate on the meaning of learner beliefs, I start from Borg's (2001) definition of belief: "A belief is a proposition which may be consciously or unconsciously held, is evaluative in that it is accepted as true by the individual, and is therefore imbued with emotive commitment; further, it serves as a guide to thought and behaviour" (p. 186). This definition to a certain degree reflects the relationship between beliefs and culture. People's knowledge of and in a culture are related to their beliefs about the norms in that culture and their attitudes toward other cultures. Because how one acquires knowledge influences how one sees the world, people's beliefs about the same concept may differ across cultures and even within the same culture. The notion of learner beliefs is important in academic settings; Woods (2003) relates learner beliefs to action in the sense that "they influence decisions, actions, events and interpretations of events" (p. 206). Because learner beliefs influence students' interpretation and evaluation of activities 
taking place in the learning process, differences in learner beliefs may result in varied decisions and actions, and therefore variable results in learning. In an ESL setting, students who move to another culture bring with them beliefs about the education system and the process of education, beliefs about written texts, and beliefs about the processes of writing and learning that may or may not match those in the Western academic context. As a result, conflicts and disagreements may arise, to add to the difficulties ESL learners have to overcome.

This article examines the relationship among these notions of culture, identity, and beliefs through a study that examines the beliefs of teachers and students in terms of language-learning and academic writing in the light of cultural influences. The interplay of cultural characteristics, writer identity, and learner beliefs is discussed in order to explore the construction of ESL writer identity and the evolution of learner beliefs about the micro- and macro-processes of ESL writing.

Because in this study the processes of writing are discussed in relation to culture and identity, I focus especially on the broader context, the macro-process in which culture, identity, and beliefs interact, shape, and are shaped by each other. I include micro-process strategies within the macro-process because the micro-process is a part of the macro-process; a series of micro-process elements constitutes part of the macro-process. I argue that the prerequisite for improvement of performance in the micro-process is a change in beliefs about the macro-process, which is especially closely bound up with cultural perceptions.

\section{The Study of Culture, Identity, and Beliefs in ESL Writing}

\section{Rationale and Data}

The study employed a qualitative case study approach. Case A involved an ongoing study of a first-year undergraduate student from China, Min (pseudonym), who was taking a credit course in EAP (English for academic purposes) and a credit course in film studies during an entire term. The goal was to examine how the participant's first language and culture influenced her English writing in a Canadian academic setting and how she managed to change her perceptions of writing in order to establish a successful ESL writer identity within a short period after her arrival in Canada. It became evident in the course of this research that issues of identity were reflected not only in the final products of her writing, but also in how she experienced the processes of writing and of learning to write. In Min's attempt to establish a successful second-language writer identity, she experienced a confusing and evolving period of beliefs about language-learning and academic writing. What came out of Case A were the cultural aspects of beliefs and how these influenced writing in an instructional setting. Based on themes from Case A, 
I started Case B with an EAP writing class in order to look at how culture and beliefs shaped and reflected each other in the micro- and the macro-processes of writing in an ESL classroom setting. In Case B the focus was on beliefs about writing and learning, but the beliefs were not treated as independent from culture because beliefs are formed and learned through cultural heritage. They intertwine and interplay, blurring distinctions among them and complicating the situations related to them. Four of the students were interviewed: Julia, Robert, Betty, and Glen (pseudonyms). They were all from East Asian countries/regions such as China, Korea, and Taiwan, and they shared a similar cultural heritage of Confucianism, Taoism, and Buddhism. The teacher, Jane (pseudonym), had 16 years' ESL teaching experience at the university level.

The data collected in Case A included field notes and interview recordings during our weekly meetings over the term, as well as the written assignments Min had completed for both courses, including some short essays and five entries in a personal-response journal for the EAP program, and an in-class test, a shot-by-shot analysis, and an essay for film studies. Our meetings usually focused on a certain assignment or a certain genre of writing with which she had problems; the interviews involved mainly semistructured questions and conversations, each time related to the particularities of the assignment in question. Our regular meetings allowed me to reexamine what had been articulated in the previous meetings and to clarify potential misunderstandings of the data. This longitudinal study also provided me with the opportunity to observe Min's progress in the macroprocess of learning to write in a Western academic setting. In other words, I was able to capture the cultural aspects and beliefs related to education as reflected in her written and spoken discourse and how these influenced her learning processes in the target language.

In Case B triangulation of data was achieved by using multiple data-collection methods and data sources to enhance the validity of the findings (Ertmer, 1997; Patton, 2002). Data were drawn from four three-hour classroom observations and from initial and follow-up one-hour interviews with the four students and with their teacher respectively (see Appendix). Initially there were two interviews, one with the four students as a group and one with the teacher; these mainly involved global questions about the macroprocess such as questions about the participants' language-learning (and language-teaching in the teacher's case) experiences, their cultural backgrounds, and their opinions on teaching methods. There were also a few micro-process questions reflecting such issues as peer review and teacher feedback on writing. The classroom observations served as a means to examine whether and how the beliefs posited by the teacher and the students in the initial interviews were reflected in classroom activities. The observations were also used as a cue for eliciting questions for the second interviews. 
The follow-up interviews were arranged after the observations, centering on more specific questions about some micro-process strategies employed in class. There were five follow-up interviews: one with the teacher, plus one with each of the four students individually.

Data were examined using the interpretational approach (Ertmer, 1997; Patton, 2002) to identify underlying themes during the process of data-collection. Earlier data analyses were used to determine subsequent data collection activities. Some of the themes became evident during the process of cyclical analysis (Lee, 2001); others surfaced at the end of the study when I put all the data together for a cross-check.

\section{Results}

In analyzing the data in Case A, I examined particularly the reconstruction and development of writer identity both in the participant's written texts, and in the micro- and the macro-processes of her writing. For Case B I mainly looked at how the students' cultural beliefs about learning and writing evolved and played a role in shaping their identity in the processes of composing and learning to compose.

\section{Product: Cultural Influence and Awkward Identity}

The data from Case A revealed a disjunction between the participant's view of higher education and academic writing and that of her teachers. This disjunction hindered her from presenting a critical self in her academic work. In the first place, her understanding of university study rested on memorybased learning instead of research-based education. This could be seen from her first in-class test for the film studies course. She scored high in section 1 Terminology, which asked her to give precise descriptions of terms such as long shot, mise en scène, eyeline match, and so forth. However, she did not do well in the second section Short Questions. Answers to such questions as "How is spatial continuity maintained in the opening of The Maltese Falcon (John Huston, 1941)?" and "How many narrative forms operate in Mike Hoolboom's Positive (1998)? Describe briefly each one," were not readily available in her notebook or textbook; she had to formulate her own answers based on her understanding of theories and specific film clips. Her responses on this test reflected difficulty in adapting to the requirement for independent thinking. Another case in point was that she understood her first analytical essay for film studies as a series of short-answer questions. She was surprised to learn that she had to research the topic and make a strong argument. She seemed to have been trapped in the gap between her home educational system, which focused on internalization of knowledge (Ballard \& Clanchy, 1991; Ramanathan \& Atkinson, 1999) and the host educational system, which emphasized originality and independent research. 
Moreover, Min's native-culture rhetorical style posed a challenge because it diverged from the host culture's expectations. In her first journal for the EAP class-analyzing her friend's decision to study in Canada instead of in another country-she used a "bush-clearing" (Shen, 1989, p. 463) pattern to approach the key point:

My friend's name is Lan Wang [pseudonym]. She comes from Shanghai, which is located in eastern China; it is a big, modern city, economic center-there are about 13 million population. Her plan is not so clear, but at least she will pursue her study until she gets her $\mathrm{PhD}$ degree if she has enough money to support her. After that, she will decide whether to go back to her motherland or work in Canada. For now, she has no idea about it.

In addition, her birthday is sharply one month earlier than mine. What a coincidence! And she has 5 cousins in all. Their relationships are close because they have lived in the same house for several years.

She decided to choose Canada as her study place because she didn't feel satisfactory about $X$ Institute [name replaced by researcher] in Shanghai. USA is not safe to study after "911" events. British tuition is too expensive compared to Canada. She never thinks of the other countries.

It took Min a long while to get to the main point, moving from her friend's home town to her future plans, her birthday, and her family, before finally discussing the reasons for her decision. This appeared confusing to her teacher, and the teacher's feedback confused Min as well. She had no idea why the teacher did not appreciate her step-by-step lead-up to the topic.

She also had difficulties dealing with the formalities of words and structures. On several occasions the teacher commented on her essays that she should use formal expressions. In our meetings she asked me about the differences between some synonyms and expressions such as replace and substitute; can be used longer, and have a longer lifespan. She found that the English she had learned before was not exactly the English she was supposed to use in academic writing. One demanding and urgent task seemed to be for her to set up a vocabulary bank of formal, abstract, and specialized "code words" (Casanave, 1992, p. 160). All the above factors prevented her from establishing a successful identity in writing at an early stage.

Processes: Confusion, Transition and Evolution of Identity

Examining these products as they were being created drew my interest to the micro-process of Min's writing. In dealing with a specific assignment, Min found it hard to locate her identity as a learner-writer in this Canadian university setting. Coming from a culture in which individual voice is usual- 
ly drowned in a sea of collective voice, she felt hesitant to write her own opinions. She told me that she was not sure what she was supposed to say in a critique of an article. "I think it is excellent. How can I criticize it when I don't see the problems?" she asked. Her native culture's emphasis on appreciating and respecting authorities hindered her from thinking critically as expected by a Western instructor. Assuming that be critical meant criticize, she stated that she was not accustomed to "picking faults of those famous people." She struggled to establish an appropriate writer identity that took account of the reader, her professor, and her teacher, as well as of the sociocultural context that supported this discourse. All her efforts were spent trying to fit into the role of what Ivanic (1994) calls a puppet on the strings of "the values and practices of [the] social context" (p. 11). This was an identity that she felt did not truly portray herself, but rather a self that satisfied a specific group of readers who were significant to her academic success.

There were some positive aspects that enabled Min eventually to progress in developing her composing skills and in altering her identity in writing to suit Western academic standards. First of all, her serious attitude toward every micro-process element practiced in class allowed her to grasp writing skills quickly. She started to see the purpose and significance of strategies such as journal-writing, critiquing, and peer revision as necessary training toward improving overall competence in writing. In addition, she was able to apply what she had newly learned to understanding the teachers' requirements and intentions for each assignment. The new insights she gained about the differences and similarities between Eastern and Western education, the conventions of English writing, and notions such as criticism and individualism in Western culture helped her gain clarity. She came to understand that the real cause of her frustration was insufficient knowledge of Western educational conventions and varied genres of academic writing. This change in beliefs about learning was a prerequisite for progress and for creating a successful identity in writing. Her improvement was evident in terms of the composing process, the written texts, and the learning process in which independence was a crucial point. Her later assignments were seldom criticized on account of organizational and argumentative issues. Min's identity as an independent, critical writer evolved out of her experience, which went beyond the influence of her first culture.

\section{Processes: Cultural Beliefs about Writing}

In Case B the relationship between the micro- and the macro-processes is one of close alignment. I compare the beliefs articulated by the four students with those expressed by the teacher. It is, however, necessary to stress that evidence of the two processes was often mixed or even integrated in their discourse. 
Interviews with these students and observations of them indicated that they entered the classroom identifying themselves according to the role into which their cultural beliefs molded them. In the interviews they perceived themselves as students influenced by "the culture of Asia," who were going to learn everything about academic writing from the teacher, the only authority in the classroom. Although they had a vague long-term goal of achieving higher proficiency in English writing, they were not able to distinguish micro-from macro-processes or to recognize the interplay between the two. Their acceptance of the teacher's micro-process strategies was based on their cultural perception of who they were and what they were supposed to do. Thus they were skeptical about peer feedback and much preferred error correction from the teacher. For example, in terms of error correction, Julia expressed a strong preference that the teacher correct her mistakes immediately so that she would be able to identify them and therefore to improve in future. Glen and Betty also wished that the teacher would point out their mistakes in every draft. On the other hand, Jane, the teacher, said, "I don't believe in error correction"; she considered language as "a minor issue" that should be dealt with at a later stage when the structure and ideas were no longer a problem. She emphasized that students would not improve until they became "ready" writers; that is, writers who were ready for the strategies practiced in class.

Jane believed that students could learn from their own mistakes and from those of their peers; whereas these students viewed self-evaluation as useless and peer evaluation as generally ineffective. They identified themselves as learners, receptacles of knowledge; so they felt that they were not in a good position to offer suggestions. In addition, they did not trust their peers' opinions because they identified their peers as being in the same role as themselves. The students' understanding of such instructional practices did not match the teacher's intention to use these activities as a way of training them to become better writers. They unanimously acknowledged learning from their teacher, but dismissed the idea of learning from peers. For example, Julia commented that only her native-speaker teacher Jane had enough knowledge to change the expression paper factory into paper mill in her writing; none of her classmates were able to do so.

While the students mainly focused on specific tasks with an ambiguous long-term goal, the teacher was thinking of the macro-process of improving students' writing through micro-process strategies. Jane encouraged the students to read extensively "for their own passion" and stressed learner independence because "the whole culture is based on independence." She considered her role as a writing instructor as one of giving feedback to the students as they moved toward the final product. In her opinion, the process of revising and improving was more important than the product. The students' response to the notion of learner independence, however, demon- 
strated a contradiction. On the one hand, they were enthusiastic about such practices as computer-lab research, which was intended to engender a sense of independent research in students. On the other hand, the students all wished Jane would be strict with them and give them moderate pressure from time to time so that they would be more disciplined in learning. Their perceptions of their own identities persistently influenced their expectations and strategies in learning: learning was not an individual endeavor, but was dependent on how and what the teacher taught.

Although in this Case I initially did not intend to focus on the issue of identity in the processes of writing, it surfaced on its own. It was not just identity as a writer; the beliefs the students articulated were more concerned with learner identity. It became clear that they saw themselves as learners from different cultures; their learner identity was influenced by their East Asian culture. And their learner identity inevitably molded their identity as writers. For example, they intentionally constructed an appreciative writer identity in their final journal submitted to the teacher to show respect for her (e.g., "I have learned a lot from you in this class."), but they conveyed different versions of their opinions on the same point in their interview with me (e.g., "I don't feel my writing has improved much since I came here."). It seems that for ESL students learning to write, what matters is not only the identities they try to create as writers, but also their identities as learners.

\section{Discussion and Implications}

These are two closely related cases, one growing out of the insights of the other. When I put the data together and did a comparative analysis (Glaser \& Strauss, 1967; Maykut \& Morehouse, 1994), I identified some recurring themes corresponding to the research questions I asked.

In the above sections I distinguish the notions of the product, the microprocess, and the macro-process for analytical purposes; however, the data show the interwoven nature of these three perspectives, which ultimately are three aspects of the same thing. Putting them together to examine how they interplay and influence each other, my argument is that the product reflects beliefs about the micro- and the macro-processes. Also, beliefs about the micro- and the macro-processes influence the quality of the product and the identity created in it.

\section{Question 1: Cultural Influence on Writer Identity and Learner Beliefs}

One of the major themes that surfaced in both cases was how profoundly and pervasively the first culture influenced the construction of writer identity and the formation of learner beliefs in an ESL setting. Poole (1992) asserts, "Second language contexts include cultural dimensions that powerfully and necessarily affect both the teaching and learning processes.... These cultural 
aspects of setting and interaction ... are the primary vehicles through which message content is conveyed" (p. 610). In Case A such cultural factors were evident in Min's writing at an early stage. Her frustrations were caused mostly by the distance between the prevailing ideologies in her first culture and those in this new target culture. Her inappropriate rhetorical style, her misunderstanding of critical reasoning, and her inadequacy in independent research were all instances of the effects of such a distance. She had to be cautious all the time in order to keep a balanced self-representation that was above both her native culture and the target culture in her writing. Examination of this case indicated that cultural influences on the product could have an underlying basis in terms of what was going on in the processes. Because of this realization, in the second case I focused on the processes.

In Case B culture was also a notion mentioned frequently by the teacher and the students. Both parties claimed awareness of cultural influences on second-language learning. However, they did not make a conscious effort to find the intersection of the two cultures. Jane was waiting for her students to get ready, while throwing out to them concepts popular in Western ESL classrooms. She was happy that she could sometimes "brainwash" them. The students, however, obeyed Jane on the surface, but complained behind her back. From my point of view, it is important for ESL teachers to see that when students learn a language, they are also learning (about) the culture that language represents; and that students are cultural beings with cultural perspectives on the world, including culture-specific expectations of the classroom and learning processes (Deng \& Liu, 1995; Wajnryb, 1992). On the other hand, it is also critical for ESL students to understand that how they compose and how they construct their identity in second-language writing is in part affected by their first language and culture, so that they may become able to compare the two systems more consciously and learn to appreciate the strengths of both instead of dreading the disparities between them. A harmonious learning environment can be created only when the teacher considers and respects the cultural dimensions of the students and the students in turn gain a positive attitude toward the culture of the target language.

One of the important issues embedded in the notion of culture hinges on perceptions and beliefs related to the roles of teacher and student in the macro-process. In Case A Min stated that her EAP teacher did not provide her with explicit information about styles of writing and did not assign her a sample text to imitate, both of which are commonly part of the teacher's role in the culture of Chinese classrooms. It seemed that by explicit contrastive analysis of the diverse cultural conventions during our meetings, I could facilitate Min's bridging of that gap in such a way that she learned to deal with conflicts in writing styles and cultural conventions. 
In Case B the students held contradictory views of the role of the teacher. On the one hand, they stated that the teacher should provide correct models, corrective feedback, and a strict learning environment in which students had no choice but to do the assigned topics and to follow the teacher's instructions. But on the other hand, they all articulated their appreciation for the "freedom" that they felt in the writing class, where the teacher's role was to be a catalyst for creative ideas and to be accommodating of imperfect language. This contradiction apparently derived from the disparity of cultural and educational backgrounds between the teacher and the students.

\section{Question 2: Identity and Beliefs in the Processes of ESL Writing}

To date research has not focused on the exploration of identity and beliefs in relation to the micro- and the macro-processes of ESL writing. This, however, was one of the themes that emerged from this study.

Awareness of the relationship between the micro- and the macro-processes of writing was sometimes implicit in Case A, as was the link between them in relation to the construction of writer identity. In my earlier meetings with Min, her immediate purpose was to get help in completing a certain assignment, which represented a focus on elements of the micro-process. However, during our meetings, both of us realized that what she needed most urgently was macro-process knowledge in such areas as the cultural elements in learning, variable beliefs about higher education, and identity construction in academic writing in the Western world. Thus a macro-process orientation underlay her effort to get help with micro-process activities. And changes in her beliefs over time were in fact part of the macro-process of learning to write for a Western academic reader.

Furthermore, the relationship between the micro- and the macro-processes was an evident theme in Case B; it represented the superordinate mismatch between the teacher's and the students' beliefs in this regard. Other mismatches seemed to be subordinate to this higher-level issue. Mismatches at both levels are in essence caused by varied cultural assumptions. Although I distinguish between these micro- and macro-processes above, I now bring them together and show the connection between them: for example, doing peer review is a micro-process strategy, but willingness or unwillingness to engage in it in the ESL classroom concerns beliefs about the macroprocess.

An emphasis on micro-process writing strategies was a key element in the writing component of the ESL program in the university where this study was conducted. For many participants this practice was far removed from the prevailing methods in the EFL settings where they had obtained their previous English education. As a result, students' views on specific aspects of process writing demonstrated complexity and contradiction. For example, the students held positive attitudes toward some strategies such as freewrit- 
ing, which focuses more on content than on language itself. They were inspired by the teacher's feedback and told Jane that they had never had teachers "comment on their thinking," because English teachers in their previous educational settings usually commented only on language. However, due to the effect of the beliefs they had already formed from prior experience, these students did not readily accept all the strategies in process writing. They were particularly doubtful about peer evaluation. The reason lay in the fact that they were accustomed to a traditional product-oriented writing process (Woods, 1984), in which students write by imitating sample texts and the teacher makes corrections. They were used to paying attention to language accuracy and expected grammar correction from the teacher, although they also claimed that they agreed with the teacher's focus on content rather than on grammatical accuracy. This result resonates with the findings of research investigating ESL students' preferences for teacher feedback on their writing (Leki, 1991; Diab, 2005). Moreover, these students believed in the authority of the teacher; they did not trust the opinions of peers who were at their own level. Further, because of their belief in authority and their lack of confidence in themselves, they were hesitant to offer their own suggestions to peers, who in turn may not have valued their suggestions for the same reason. The disparity between the beliefs of the teacher and of the students and the contradiction between students' own stated beliefs and their implicit expectations reflect the complex reality in the ESL setting.

Complexity could also be observed in the macro-process through which students understood basic assumptions and grasped writing skills as a result of practice over time and through cultural awareness. The data indicated disagreements between the teacher and the students in terms of the deeperlevel relationship between the micro- and the macro-processes. As shown in earlier discussions, every time the teacher talked about micro-process strategies, her intention was to relate them to the macro-process so as to improve students' competence in writing through these specific practices. Her micro-process strategies were in fact macro-oriented. Each of the microprocess activities was thought of in the light of past and future micro-processes, creating a framework that constituted the macro-process. However, students saw each of these activities as discrete tasks that did not connect with each other. This difference in beliefs and interpretations seemed to underlie many other disagreements about micro-process elements and also appeared to complicate the macro-process situation.

However, there were some positive instances. First, the teacher and the students shared an appreciation for independent learning. This would eventually turn teacher-dependent, sample-text-directed learning into self-dependent, research-directed writing practice. The influence of this respect could be substantial for the students should they remain in a setting where 
good writing competence is a prerequisite for success. In addition, the teacher and the students shared a moderate degree of cultural awareness. Although not ideal, it facilitated understanding between the teacher and the students, as well as among the students. In ESL contexts, if teachers and students make concerted efforts to raise shared cultural awareness, it will help both parties to understand that culturally divergent norms pertaining to writing do not imply that a certain culture is superior or inferior, but rather that learning to write in a second language means adapting oneself to that second language's culture: other writing traditions are simply handed down as cultural heritages, and an appropriate text in one culture may not be appropriate in another context. Teachers can work more efficiently by leading their students to an exploration of the cultural and educational characterisctics of students' home and host learning settings, taking care not to impose the writing practices valued in the Western academy without a satisfying explanation. Agreement between teacher and students will ultimately be beneficial to students' endeavor to establish a successful writer identity.

\section{Question 3: Evolution of Learner Beliefs and Its Implications}

The evolution of beliefs is important in both cases. The beliefs reflected in them are interconnected, not discrete; they "are not stable entities within the individual, but situated in social contexts and formed through specific instances of social interaction and, as a result, are constantly evolving" (Woods, 2003, p. 200). In both Cases A and B students experienced a puzzling period in the process of changing beliefs and identities in their second-language writing. The students in Case B entered their writing class with existing beliefs about language-learning formed through prior educational experience; however, they were in the process of altering their beliefs to fit into the new learning environment. They accepted freewriting, which was a new writing strategy for them. They were doing revisions; they were learning the structure of English argumentative writing. They became aware of the importance of individual research ability, and their keen interest in Web-based research was a sign of emerging learner independence. Indeed, "the formation and development of beliefs can be seen as a type of learning" (p. 200). However, at a mental level they were still wandering at the junction of their first culture and second culture, longing for pushes from external forces such as the teacher. Their beliefs about learning and writing were in the process of evolution. This process was influenced first of all by the teacher's beliefs. It was also altered by the educational setting of which they had become a part. Min went through a similar process. The difference was that her process of reformulating new beliefs about academic work seemed shorter. She seemed to be already on the right track to reconstruct an appropriate ESL writer identity. This track was smoothed by two streams of 
instruction: general advice from her EAP class and diagnostic advice from me in our meetings as a complement to classroom learning.

When students and teachers first meet in an ESL class, their perceptions and beliefs may not overlap significantly. It is through negotiation and effort to understand each other that students start to change their ideas and move closer to their teachers' beliefs. It may take students varying lengths of time to understand the teacher's philosophy of teaching. However, we need to ask to what extent teachers should explicitly articulate their beliefs to students. Give them a gentle push, or just wait until they are ready to understand the teacher? And are teachers' beliefs subject to adjustment with respect to various components of students' beliefs in a given class? There are also cases when there is a lack of evolution in students' learning. In such cases, how can teachers assist learners to speed up their progress?

ESL writers from diverse cultures or societies have been acculturated in particular ways with regard to language use and have learned the discourse conventions of their respective cultures or societies; they bring various cultural experiences to their writing experiences and may encode meaning in ways that are different from the target culture. Strevens (1987) advocates that language teachers assist learners to compare the various cultural presuppositions between the target culture and their own culture so that they are able to cope with and appreciate both the diversity and equality of human society. Lu (1987) also suggests that instructors not teach students to "'survive' the whirlpool of crosscurrents by avoiding it"; instead, teachers are advised to "use the classroom to moderate the currents, but teach them from the beginning to struggle" (p. 447). At a practical level, this means that teachers should assist students in learning the similarities and differences between their first culture and the host culture so that the macro-process may be learned more consciously and the micro-process strategies may make more sense to them. Abruptly imposing the recognized practices of Western academic culture may intimidate and overwhelm students, whereas withholding cultural capital and leaving students to fumble may deprive them of opportunities for faster academic growth and smoother evolution in their beliefs and identities.

\section{Conclusion}

To date a great number of studies have contributed to the exploration of cultural differences, including cultural influences on written ESL texts and on the strategies used in the processes of ESL writing. However, the construction of writer identity and the evolution of learner beliefs as a result of multiple cultural influences in second-language writing have been insufficiently addressed. This study focused on the dynamic relationship among culture, identity, and beliefs with regard to the micro- and macro-processes of ESL writing. Findings from the study indicate that the notions of culture, 
identity, and beliefs are tightly interwoven. They interconnect and interplay, and they work together to shape learner beliefs about education in general and about writing in particular; they also work together in the reconstruction of an ESL writer's identity, incorporating multiple influences and intentions. However, the evolution of beliefs involved in an ESL writer's adaptation to a new learning context and construction of a new writer identity in that context is doubtless a daunting task. ESL teachers are advised to "moderate the currents" (Lu, 1987, p. 447) by guiding their students in the exploration of cultural norms in varied educational contexts-instead of withholding cultural capital—so as to facilitate the reformulation and evolution of writer identity and learner beliefs.

\section{Acknowledgments}

I thank Devon Woods for his support during the research and his helpful comments on an earlier draft of this article. I also thank the anonymous reviewers for their generous suggestions for revisions.

\section{The Author}

Xuemei Li is a doctoral candidate in the Faculty of Education, Queen's University, Canada. She has had 17 years of EFL/ESL teaching and research experience in China, England, and Canada. Her research interests cover sociocultural aspects of second-language education with a focus on identity issues in ESL contexts.

\section{References}

Ashwell, T. (2000). Patterns of teacher response to student writing in a multiple-draft composition classroom: Is content feedback followed by form feedback the best method? Journal of Second Language Writing, 9(3), 227-257.

Ballard, B., \& Clanchy, J. (1991). Assessment by misconception: Cultural influences and intellectual traditions. In L. Hamp-Lyons (Ed.), Assessing second language writing in academic contexts (pp. 19-35). Norwood, NJ: Ablex.

Borg, M. (2001). Teacher beliefs. ELT Journal, 55(2), 186-188.

Carson, J.G., \& Nelson G.L. (1996). Chinese students' perceptions of ESL peer response group interaction. Journal of Second Language Writing, 5(1), 1-19.

Casanave, C.P. (1992). Cultural diversity and socialization: A case study of a Hispanic woman in a doctoral program in sociology. In D.E. Murray (Ed.), Diversity as resource: Redefining cultural literacy (pp. 148-183). Alexandria, VA: TESOL.

Connor U., \& Lauer, J. (1988). Cross-cultural variation in persuasive student writing. In A. Purves (Ed.), Writing across languages and cultures: Issues in contrastive rhetoric (pp. 138-159). Newbury Park, CA: Sage.

Clark, R., \& Ivanic, R. (1997). The politics of writing. New York: Routledge.

Cortazzi, M., \& Jin, L. (1996). Cultures of learning: Language classrooms in China. In H. Coleman (Ed.), Society and the language classroom (pp. 169-206). Cambridge, UK: Cambridge University Press.

Deng, Y., \& Liu, R. (1995). Language and culture: English-Chinese contrastive culture studies. Beijing: Foreign Language Teaching and Research Press.

Diab, R.L. (2005). Teachers' and students' beliefs about responding to ESL writing: A case study. TESL Canada Journal, 23(1), 28-43. 
Donaldson, S. (1990). Intensive courses at CALS. In W. Magahay \& D. Woods (Eds.), Carleton papers in applied language studies, 7 (pp. 6-85). Ottawa: Center for Applied Language Studies, Carleton University.

Ertmer, P. (1997). Common qualitative research designs. In P. Leedy \& J. Ormrod (Eds.), Practical research: Planning and design (pp. 155-172). Upper Saddle River, NJ: Prentice-Hall.

Ferris, D.R. (1999). The case for grammar correction in L2 writing classes: A response to Truscott (1996). Journal of Second Language Writing, 8(1), 1-11.

Ferris, D.R. (2004). The "grammar correction" debate in L2 writing: Where are we, and where do we go from here? (and what do we do in the meantime ...?). Journal of Second Language Writing, 13(1), 49-62.

Ferris, D.R., \& Roberts, B. (2001). Error feedback in L2 writing classes: How explicit does it need to be? Journal of Second Language Writing, 10(3), 161-184.

Glaser, B., \& Strauss, A. (1967). The discovery of grounded theory: Strategies for qualitative research. Chicago, IL: Aldine.

Hedgcock, J., \& Lefkowitz, N. (1994). Feedback on feedback: Assessing learner receptivity to teacher response in L2 composing. Journal of Second Language Writing, 3(2), 141-163.

Hinkel, E. (1994). Native and nonnative speakers' pragmatic interpretations of English texts. TESOL Quarterly, 28, 353-376.

Hinkel, E. (1995). The use of modal verbs as a reflection of cultural values. TESOL Quarterly, $29,325-343$

Hirvela, A., \& Belcher, D. (2001). Coming back to voice: The multiple voices and identities of mature multilingual writers. Journal of Second Language Writing, 10(1-2), 83-106.

Horwitz, E. K. (1999). Cultural and situational influences on foreign language learners' beliefs about language learning: A review of BALLI studies. System, 27(4), 557-576.

Hyland, F. (1998). The impact of teacher written feedback on individual writers. Journal of Second Language Writing, 7(3), 255-286.

Hyland, F., \& Hyland, K. (2001). Sugaring the pill: Praise and criticism in written feedback. Journal of Second Language Writing, 10(3), 185-212.

Hyland, K. (2002). Options of identity in academic writing. ELT Journal, 56(4), 351-358.

Ivanic R. (1994). I is for interpersonal: Discoursal construction of writer identities and the teaching of writing. Linguistics and Education, 6, 3-15.

Ivanic, R. (1997). Writing and identity: The discoursal construction of identity in academic writing. Philadelphia, PA: John Benjamins.

Jacobs, G., Curtis, A, Braine, G., \& Huang, S. (1998). Feedback on student writing: Taking the middle path. Journal of Second Language Writing, 7(3), 307-317.

Johnson, K. (1995). Undersatanding communication in second language classroom. Cambridge, UK: Cambridge University Press.

Kaplan, R. (1966). Cultural thought patterns in inter-culture education. Language Learning, 16(1-2), 1-20.

Kaplan, R. (1987). Cultural thought patterns revisited. In U. Connor \& R. Kaplan (Eds.), Writing across languages: Analysis of L2 text (pp. 9-20). Reading, MA: Addison-Wesley.

Kramsch, C. (1998). Language and culture. Oxford, UK: Oxford University Press.

Lee, H. (1999). Investigation of freewriting activities in ESL process writing classrooms. Unpublished master's thesis, School of Linguistics and Applied Language Studies, Carleton University.

Lee, J. (2001). Exploring dynamic perspectives on L2 learning motivation: A qualitative inquiry of three adult Korean ESL learners. Unpublished master's thesis, Carleton University.

Lee, T. (2000). Education in traditional China: A history. Leiden: Koninklijke Brill NV.

Leki, I. (1991). The preferences of ESL students for error-correction in college-level writing classes. Foreign Language Annals, 24, 203-218.

Leki, I., \& Carson, J. (1994). Students' perceptions of EAP writing instruction and writing needs across disciplines. TESOL Quarterly, 28, 81-101.

Lu, M. (1987). From silence to words: Writing as struggle. College English, 49(4), 437-448 
Mangelsdorf, K., \& Schlumberger, A. (1992). ESL student response stances in a peer-review task. Journal of Second Language Writing, 1(3), 235-254.

Maykut, P., \& Morehouse (1994). Beginning qualitative research: A philosophical and practical guide. London: Falmer Press.

Mendonça, C., \& Johnson, K. (1994). Peer review negotiations: Revision activities in ESL writing instruction. TESOL Quarterly, 28, 745-769.

Nelson, G., \& Carson, J. (1998). ESL students' perceptions of effectiveness in peer response groups. Journal of Second Language Writing, 7(2), 113-131.

Nisbett, R.E., Peng, K., Choi, I., \& Norenzayan, A. (2001). Culture and systems of thought: Holistic versus analytic cognition. Psychological Review, 108(2), 291-310.

Nunan, D. (1989). Designing tasks for the communicative classroom. Cambridge, UK: Cambridge University Press.

Paulus, T.M. (1999). The effect of peer and teacher feedback on students writing. Journal of Second Language Writing, 8(3), 265-289.

Patton, M. (2002). Qualitative research and evaluation methods (2nd ed.). Thousand Oaks, CA: Sage.

Poole, D. (1992). Language socialization in the second language classroom. Language Learning, 42(4), 593-616.

Ramanathan, V., \& Atkinson, D. (1999). Individualism, academic writing, and ESL writers. Journal of Second Language Writing, 8(1), 45-75.

Shen, F. (1989). The classroom and the wider culture: Identity as a key to learning English composition. College Composition and Communication, 40(1), 459-466.

Stanley, J. (1992). Coaching student writers to be effective peer evaluators. Journal of Second Language Writing, 1(3), 217-233.

Strevens, P. (1987). Cultural barriers to language learning. In L. Smith (Ed.), Discourse across cultures: Strategies in world Englishes (pp. 169-178). New York: Prentice-Hall.

Thornborrow, J. (1999). Language and identity. In L. Thomas \& S. Wareing (Eds.), Language, society and power: An introduction (pp. 135-149). London: Routledge.

Tweed, R., \& Lehman, D. (2002). Learning considered within a cultural context: Confucian and Socratic approaches. American Psychologist, 57(2), 89-99.

Truscott, J. (1996). The case against grammar correction in L2 writing classes. Language Learning, 46(2), 327-369.

Truscott, J. (1999). The case for "The case against grammar correction in L2 writing classes": A response to Ferris. Journal of Second Language Writing, 8(2), 111-122.

Wajnryb, R. (1992). Classroom observation tasks: A resource book for language teachers and trainers. Cambridge, UK: Cambridge University Press.

Woods, D. (1984). A process orientation in ESL writing. In L. Young (Ed.), Carleton papers in applied language studies, 1 (pp. 101-138). Ottawa: Center for Applied Language Studies, Carleton University.

Woods, D. (2003). The social construction of beliefs in the language classroom. In A. Barcelos \& P. Kalaja (Eds.), New approaches to research on beliefs about SLA (pp. 199-227). Dordrecht: Kluwer Academic.

Zamel, V. (1983). The composing processes of advanced ESL students: Six case studies. TESOL Quarterly, 17, 165-187.

Zhang, S. (1995). Reexamining the affective advantage of peer feedback in the ESL writing class. Journal of Second Language Writing, 4(3), 209-222.

$\mathrm{Zhu}, \mathrm{W}$. (2001). Interaction and feedback in mixed peer response groups. Journal of Second Language Writing, 10 (4), 251-276. 


\section{Appendix \\ Sample Interview Questions}

Case B: Initial Interview Questions for the Teacher

I. Could you please briefly describe your education background and work experience?

1. Have you ever been educated in countries other than Canada?

2. Have you ever worked in other countries?

3. How long have you been teaching ESL?

4. Have you seen any changes in the composition of your students through these years?

5. If yes, what are the changes? Have you found a certain trend?

II. How much do you know about your students?

1. What cultures do your students come from?

2. How do you know?

3. Do you know their educational backgrounds and the educational systems in their countries?

III. What do you think of your teaching method?

1. Have you ever encountered any students who are not very interested in your teaching?

2. If yes, what do you think are the reasons?

3. If no, do you consider your teaching very successful?

4. Do you often consult students about their needs and their opinions on your teaching method and course content? If yes, can you list a couple of things you have got from your students?

5. Do you think communicative language teaching is most effective in ESL settings?

III. What do you think is most important in ESL teaching in terms of content?

1. Do you teach grammar explicitly in class?

2. How do you handle the situation when students ask you to explain grammar rules to them?

3. Do you attach more importance to learning strategies or knowledge of the language and culture?

4. Do you have a textbook for students to read? Is it better to teach with or without a textbook?

IV. How do you usually mark students' writing?

1. What is your focus when you mark students' writing, accurate grammar and vocabulary, or content and structure?

2. Do you comment more on good points or problems? Do you pick out their errors?

3. Do you think your comments influence students' writing?

4. Do you think your comments are what students expect to get from you?

5. Do you find students repeat mistakes you have pointed out? If yes, what are the reasons?

$V$. Do you think your students understand what you have done in and out of the classroom?

1. Do you think your students appreciate your teaching method? 
2. If no, how do you handle the situation?

3. Do you think your students are being influenced by your perceptions of language learning and teaching? How do you know?

4. Do you tell students explicitly the purposes of the activities you have designed for them and the reasons why you comment on their writing in your way?

5. If yes, do you think this helps to build up understanding between you and students?

Case B: Follow-up Interview Questions for the Teacher

1. In my first observation, you asked the students to read out loud in order to find out the problems. Why?

2. But students did not do as they were told. Do you find this class more silent than other classes?

3. Do you think reading and listening help them with their writing when you ask them to read more and listen more?

4. Do you think the "Putting back the punctuation" activity helps to improve students' writing?

5. Do you think multiple revisions of the same piece of writing are good to improve their writing?

6. Do you find it's more valuable for students to evaluate their own writing or to evaluate someone else's writing?

7. Do you know what students expected to learn when they entered this class at the beginning?

8. What is the purpose of collecting portfolio writing?

Although the above thematic outlines were followed for both the first and second interviews in Case B, the questions were asked in different ways in accordance with the flow of the conversations. First and second interview questions for students in Case B were about similar foci but were asked from the students' perspective. 